\title{
An Investigation of Visual Components of Packaging on Food Consumer Behavior
}

\author{
Golnesa Ahmadi \\ Department of Management, Naragh Branch \\ Islamic Azad University, Naragh, Iran \\ E-mail: nesa_ahmadi2010@yahoo.com \\ Hamid Reza Bahrami \\ Department of Management, Naragh Branch \\ Islamic Azad University, Naragh, Iran \\ E-mail: drbahrami@yahoo.com \\ Mona Ahani (Corresponding author) \\ Department of Management, Young Researchers Club, Naragh Branch \\ Islamic Azad University, Naragh, Iran \\ E-mail: mona.ahani@yahoo.com
}

Received: June 2, 2013 Accepted: June 16, 2013

doi:10.5296/ber.v3i2.3799 URL: http://dx.doi.org/10.5296/ber.v3i2.3799

\begin{abstract}
The present research is aimed to identify the effect of components of packaging on the behavior of food consumers. In this respect, first a deep examination of literature and the internal and external studies was performed in order to find out the fundamental basis for drawing out necessary prerequisites of measuring effects of packaging components. Accordingly, product package color, package design, and the size of the food package were identified as the fundamental factors influencing the behavior of food consumers. Thus, the research assumptions were regulated.
\end{abstract}


One sample t-test was used to assess the assumptions. In order to analyze the view of respondents based on gender, an independent two sample t- test was used, and in order to analyze their views based on the level of education, income and age, a variation analysis test was used. The results show that the color of packaging, size of packaging and design of packaging have an influence (95\% confidence) on the behavior of the consumer ranking the effectiveness of individual aspects shows that the color of packaging has the highest effect on the behavior of consumers.

Keywords: Consumer behavior, Packaging, Color, Design, Size

\section{Introduction}

The consumer and his satisfaction are the essential matters which can lead to the promotion of an organization in the present competitive world. The importance of the consumer and his satisfaction relate to global competition. Therefore it is important to consider what factors can be effective more exactly and completely in increasing the satisfaction of the customers.

The role of packaging as a means of communication with the consumer and choosing trademarks is growing constantly. In order to fulfill the communication goals, it is necessary for the producers to acquire adequate information regarding the customer's psychology. On the other hand, the behavior of the consumer has been a major issue of interest for the marketing researchers during the last decades. Variation of consumer behavior is because of the effect of different factors influencing the behavior and motivation of the person for purchase. The existence of different groups of consumers for the markets of a single product indicates wide differences. The consumer is considered today as the major key to the success or the failure of a company.

Identification of these relations and examination of the role of different packaging components in the behavior of the consumer will undoubtedly identify the strengths and the weaknesses of the companies for entering into competitive markets. Therefore the essential question of the present research is how the different aspects of product packaging influence the purchasing behavior of the consumer. In another word, how the individual aspects of product packaging, i.e color, design and the size of packaging influences the purchasing behavior of the consumer?

\section{Literature}

\subsection{Consumer Behavior}

Without knowing how the consumer behaves and without proper understanding of his behavior, organizations can not take appropriate measures to meet the requirements and needs of the consumer (Hawkins and Coney, 2010). The behavior of the consumer consists of knowledge and emotions that people experience and the actions they perform during the process of consumption. It also includes some elements of the environment that influence the knowledge, emotions and behavior. Consumers have dynamic behavior since knowledge, thoughts, emotions and the behavior of the consumer individually, and the target groups of consumers and the society as a whole are changing constantly. The dynamic nature of the consumer behavior makes the development of marketing strategies difficult. There are additional 
different definitions of the consumer behavior. For instance, American Marketing Association defines consumer behavior as follows: "Dynamic interaction of influence, recognition, behavior, and the environment that people exchange in their lives."

The behavior of a consumer consists of the interaction of thoughts, emotions, behavior, and the environment. Therefore the marketing agents need to know for instance what products and trademarks are meaningful for the consumer, how the consumer purchases, and what factors influence purchase and consumption. In addition, the behavior of consumers includes the interaction among humans. It means that the people give a valuable thing and take another thing in return (Peter and C.Olson, 2009: 115).

\subsection{Research Views about Consumer}

Decision making view: This view suggests that the consumers are rational. When considering the decision making view of purchase, we find that the consumers first find out a problem and during some steps they try to solve it rationally. These steps include problem identification, research, evaluation, choosing, and after -purchase evaluation.

Experimental view: The experimental view of the consumer purchase process suggests that the consumers sometimes do not purchase based on rational decision making. Rather, they sometimes purchase goods or services only for enjoyment, imagination, excitement, and emotions.

Behavioral effect view: The behavioral effect occurs when strong environmental forces drive the consumer to buy a product without strong pre -shaped emotions or beliefs. At this time, the purchase results from the direct influence of behavior through environmental forces including the means of sale promotion, cultural norms, physical environment or economic stresses (Moon and Minor, 2003).

\subsection{The reason for Studying Consumer Behavior}

The development of research about consumer behavior results from a shift in marketing philosophy from the tendency of production and product towards the tendency of sale and then marketing. Additional factors contributing in the development of research about consumer behavior includes: the higher rate of introducing new products, the lower product life -cycle, increasing the movements of consumer support by private groups and public policy makers, paying attention to environment and growth of service marketing (Golchinfar and Bakhtaee, 2007).

Table 1. Reasons for studying customer behavior; source: Moon \& Minor, 2003, 28

\begin{tabular}{l} 
Reasons for studying customer behavior \\
\hline 1- The basis for marketing management should be the analysis of consumer behavior. \\
This helps the managers in the following way: \\
A) Mixed design marketing \\
B) Market segmentation \\
C) Identifying the location and product differentiation \\
D) Improvement of environmental analysis
\end{tabular}


E) Development of market research demands

2- Consumer behavior should play an important role in general policy making.

3- The study of consumer behavior transforms individual to a more efficient consumer.

4- The study of consumer behavior provides information about the consumption behavior of human being.

The study of consumer behavior provides three types of information:

A) Consumer orientation

B) Realities about human behavior

C) Viewpoints which guide the process of thinking

\subsection{Notion of Packaging}

Product packaging is any kind of dish or package within which the product is offered for sale in the market or by which the necessary information about the product is transferred to the consumer (Roosta et al, 2009: 216). Packaging is described as a harmonic system in order to prepare goods for transportation, distribution, storage, sale and consumption (Walter, 2005: 17).

\subsection{Position of Packaging in Marketing}

Packaging is an element mingled with marketing. It means every manager or marketing expert or a person who wants to study in any way about an institution and its products, needs to study and examine the different methods and kinds of product packaging of that institution and this examination should be made in two areas of protection and information. Shape, color, design and packaging are important elements in the examination of goods and a combination of these elements constitutes the superficial shape of goods in the eyes of the consumer(Silaloy \& Spice, 2004).

\section{Research Objectives}

The present research aims to investigate the relation between packaging components and consumer behavior and to obtain the following objectives:

Primary objectives: recognition and determination of the relation between packaging components and consumer behavior.

Secondary objectives:

1. recognition and determination of the relation between the color of packaging and consumer behavior

2. recognition and determination of the relation between the design of packaging and consumer behavior

3. recognition and determination of the relation between the size (volume) of packaging and consumer behavior

\section{Research Assumptions}

Primary assumption: There is a meaningful relation between the components of packaging and consumer behavior. 


\section{I Macrothink}

Secondary assumptions:

- There is a direct and meaningful relation between the color of packaging and consumer behavior.

- There is a direct and meaningful relation between the design of packaging and consumer behavior.

- There is an indirect and meaningful relation between the size (volume) of packaging and consumer behavior.

\section{Research Conceptual Model}

Based on research conceptual framework, a research conceptual model can be offered. This model shows the effect of an individual dimension of product packaging on consumer behavior. Every dimension of product packaging, i.e color, size and design is considered an independent variable. The conceptual model of research includes the primary variables and relations among them shown in figure (1).

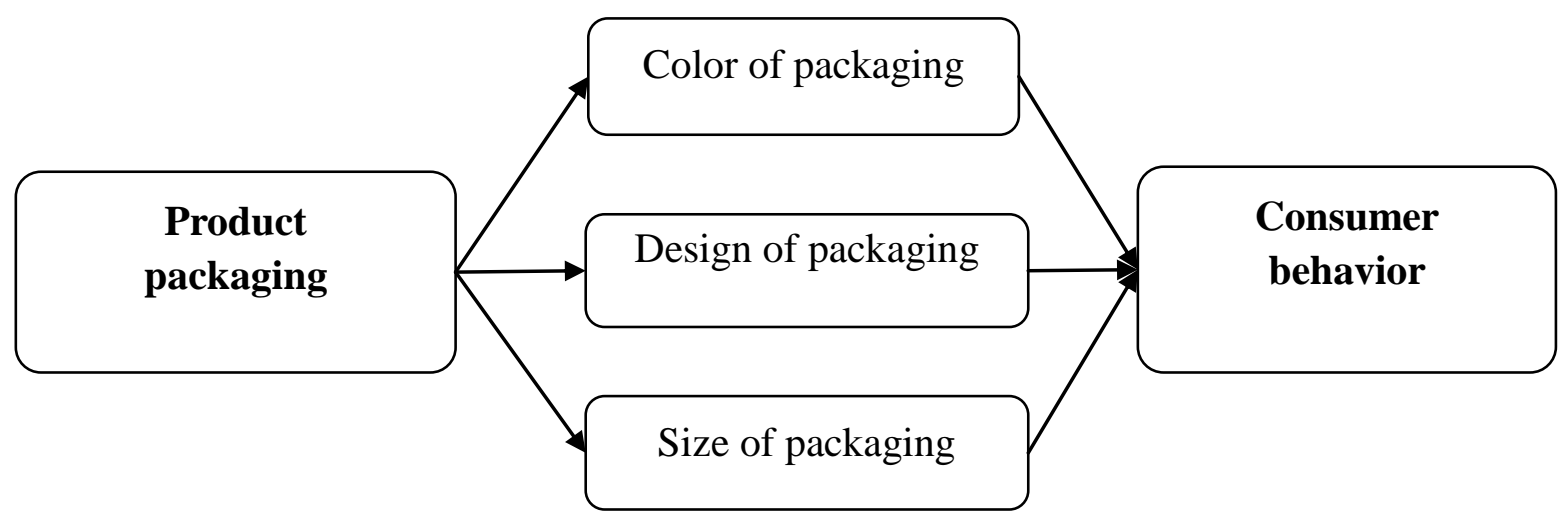

Figure 1. Research analytical model

\section{Research Method}

Since the present research aims primarily to identify the effect of every aspect of product packaging on food consumer behavior, it can be said that the purpose of present research falls in the domain of practical research. On the other hand, since the present research has used a library study method as well as a field study methods like questionnaire, it can be said that the nature and method of the present research is a descriptive-survey method.

The questionnaire used in this research includes two groups of general and specific questions. General questions are about gender, age and level of education which constitute personal specifications of the respondents. Specific questions include 19 items designed based on assessment and evaluation of individual resumptions of the thesis. Likert scale was used for the quantitative evaluation and scoring of the specific questions.

A statistical sample of the present research is obtained by the following formula: 


$$
n=\frac{Z_{\frac{\alpha}{2}}^{2} \times S^{2}}{d^{2}}
$$

In which the major parameter to estimate is $S^{2}$ which is the variance of the original sample. In order to measure $\mathrm{S}^{2}$, a number of questionnaires were distributed and the variance of the original sample was measured.

$\mathrm{n}=\left(\mathrm{Z}_{\alpha / 2}^{2} \times \mathrm{S}^{2}\right) / \mathrm{d} 2$

$\mathrm{Z}_{\alpha / 2}=1.96 \rightarrow \mathrm{Z}_{\alpha / 2}^{2}=3.8416$

$\mathrm{d}=0.05$

$\mathrm{S}^{2}=0.0732$

$\mathrm{n}=(0.0732 \times 3.8416) / 0.0025 \approx 112.482$

Considering the result obtained, 110 individuals was determined as the sample volume .In order to determine the validity of the questionnaire, the content needed validation. To do so, the questionnaire was distributed among a group of experts, and professors of management and behavior sciences, and then all of the deficiencies and ambiguities were removed. In order to evaluate the reliability of the questionnaire, 15 questioners were distributed in a primary study and the confidence correlation was measured based on Cronbach's alpha using SPSS statistical software and the number 0.724 obtained which shows the reliability of a questionnaire.

\subsection{Analysis of Data Relating to the General Specifications of Respondents}

This part describes the data relating to general specifications of the respondents, i. e. gender, age, level of education and income.

Gender: 49 individuals of the total respondents $(62.7 \%)$ were female and $37.3 \%$ were male.

Age: The respondents were classified into four groups according to their age. 47 respondents were $30-40$ years old. This number has the highest frequency with almost $43 \%$ of the total respondents. $15 \%$ of the sample (16 respondents) was $40-50$ years old. 45 respondents were below 30 years old and 2 respondents were 50 years old.

Education: 49 respondents with a bachelor's degree had the highest frequency. The individuals with a diploma and below diploma constituted $12.7 \%$ (41 respondents) of the sample. The individuals with an A.M and higher degree (6 respondents) had the lowest frequency. 14 respondents had a technician degree.

Income: 37 respondents in the present research have a monthly income lower than 300 thousand Tomans ${ }^{1}$ which constitute almost $32 \%$ of the selected sample. 11 respondents $(10 \%)$ have an income of 300-400 thousand Tomans. The people with an income higher than 600 thousand Tomans (26 respondents) constituted $26 \%$ of the sample volume.

\subsection{Research Assumptions Tests}

First, research assumptions were tested using one sample t-test.

\footnotetext{
${ }^{1}$. Iranian currency
} 
Assumption 1 test: The color of packaging influences food consumer behavior.

In order to test this assumption, $\mathrm{H}_{0}$ assumption is regulated in such a way that the color of packaging has no effect on consumer behavior and $\mathrm{H}_{1}$ is considered the opposite assumption and test claim. The statistical test assumptions are expressed as follows:

The results of assumption 1 test show that $\mathrm{H}_{0}$ is rejected at an error level of $\alpha=\% 5$ and $\mathrm{H}_{1}$ is accepted. Therefore, the color of packaging influences consumer behavior with $95 \%$ confidence interval.

Table 2. One sample t-test of assumption 1

\begin{tabular}{|c|c|c|c|c|}
\hline Assumption 1 & Average & $\mathrm{t}$ & $\begin{array}{c}\text { Degree of } \\
\text { freedom }\end{array}$ & $\mathrm{p}$ \\
\hline $\begin{array}{c}\text { Color of } \\
\text { packaging }\end{array}$ & 3.956 & 17.944 & 109 & 0.000 \\
\hline
\end{tabular}

Assumption 2 test: The size of packaging influences food consumer behavior.

In order to test this assumption, $\mathrm{H}_{0}$ is regulated in such a way that the size of packaging has no effect on consumer behavior and $\mathrm{H}_{1}$ is considered the opposite assumption and test claim. The statistical test assumptions are expressed as previous:

The results of assumption 2 test (table 3 ) show that $\mathrm{H}_{0}$ is rejected with $95 \%$ confidence and $\mathrm{H}_{1}$ is accepted. In another word, the color of packaging influences consumer behavior with $95 \%$ confidence.

Table 3. One sample t-test of assumption 2

\begin{tabular}{|c|c|c|c|c|}
\hline Assumption 2 & Average & $\mathrm{t}$ & $\begin{array}{c}\text { Degree of } \\
\text { freedom }\end{array}$ & $\mathrm{p}$ \\
\hline $\begin{array}{c}\text { Size of } \\
\text { packaging }\end{array}$ & 3.941 & 18.164 & 109 & 0.000 \\
\hline
\end{tabular}

Assumption 3 test: The design of packaging influences food consumer behavior.

In order to test this assumption, $\mathrm{H}_{0}$ is regulated in such a way that the design of packaging has no effect on consumer behavior and $\mathrm{H}_{1}$ is considered the opposite assumption and the test claim. The statistical test assumptions are expressed as follows:

Here again, based on the results of one sample t-test (table 4), $\mathrm{H}_{0}$ is rejected at an error level of $\alpha=\% 5$ and test claim is accepted. In another word, design of packaging influences consumer behavior with $95 \%$ confidence.

Table 4. One sample t-test of assumption 3

\begin{tabular}{|c|c|c|c|c|}
\hline $\begin{array}{c}\text { Assumption } \\
3\end{array}$ & Average & $\mathrm{t}$ & $\begin{array}{c}\text { Degree of } \\
\text { freedom }\end{array}$ & $\mathrm{p}$ \\
\hline $\begin{array}{c}\text { Size of } \\
\text { packaging }\end{array}$ & 3.487 & 6.503 & 109 & 0.000 \\
\hline
\end{tabular}




\section{Research Findings}

After analysis of research assumptions about gender, age, education, and income of respondents, data obtained from the research was examined further.

\section{Examination of respondents' views based on gender}

In order to measure the meaningfulness of the difference of average scores of respondents' views based on gender about the effect of packaging components on food consumer behavior, an independent two-sample test was used. This test is used when the researcher deals with two independent groups. The output of this test was examined based on variance sameness using Levine's test and through SPSS software.

In this test $\mathrm{H}_{0}$ assumption is regulated in such a way that there is no meaningful difference between the average scores of male and female respondents and that $\mathrm{H}_{2}$ is the opposite assumption. This is the statistical representation of this assumption, and is therefore based on the results obtained from assumption tests. It can be said that both men and women believe that color, design and size of packaging influences purchase behavior. The degree of influence is also the same in the views of both men and women and no meaningful difference was seen.

Table 5. Data obtained from independent two-sample test based on gender

\begin{tabular}{|c|c|c|c|c|}
\hline Assumption & $\begin{array}{c}\text { Average } \\
\text { score } \\
\text { Men's } \\
\text { views }\end{array}$ & $\begin{array}{c}\text { Average } \\
\text { scores } \\
\text { Women's } \\
\text { views }\end{array}$ & $\mathrm{F}$ & $\mathrm{P}$ \\
\hline $\begin{array}{c}\text { Color of } \\
\text { product }\end{array}$ & 4.000 & 3.929 & 0.794 & 0.375 \\
\hline $\begin{array}{c}\text { Size of } \\
\text { product }\end{array}$ & 3.455 & 3.507 & 1.445 & 0.232 \\
\hline $\begin{array}{c}\text { Design of } \\
\text { product }\end{array}$ & 3.982 & 3.917 & 0.432 & 0.512 \\
\hline
\end{tabular}

\section{Examination of respondents' views based on age}

In order to measure the meaningfulness of the difference of respondents' views based on age, single-agent variance analysis was used. This test is used for the analysis of more than two independent groups. Statistical assumptions of the test were regulated in such a way that $\mathrm{H}_{0}$ assumption, that there is no meaningful difference in respondents' views based age, was rejected when $\mu_{i} \neq \mu_{j}$ for at least one of the average scores and that $H_{1}$ is the opposite assumption.

Statistical representation of this assumption is as follows:

Based on findings and the calculated p-value, there is no meaningful difference in average scores of respondents' views based on age about any research assumptions at $\mathrm{P} \leq \% 5$ among 4 different age groups. Therefore, the people's view in different age groups, about the influence of packaging components on food consumers' behavior is the same with $95 \%$ confidence. 


\section{Macrothink}

Business and Economic Research

ISSN 2162-4860

2013, Vol. 3, No. 2

Table 6. single-agent variance analysis for examination of respondents' view based on age

\begin{tabular}{|c|c|c|}
\hline Assumption & $\mathrm{F}$ & $\mathrm{P}$ \\
\hline $\begin{array}{c}\text { Color of } \\
\text { product }\end{array}$ & 0.062 & 0.980 \\
\hline $\begin{array}{c}\text { Size of } \\
\text { product }\end{array}$ & 0.737 & 0.532 \\
\hline $\begin{array}{c}\text { Design of } \\
\text { product }\end{array}$ & 0.627 & 0.599 \\
\hline
\end{tabular}

\section{Examination of respondents' views based on academic paper}

In order to measure the meaningfulness of the difference of respondents' views based on academic paper, a single-agent variance analysis was used, since here again there are more than two independent groups. A statistical test is regulated in such a way that in the $\mathrm{H}_{0}$ assumption, there is no meaningful difference in respondents' views based on academic paper is rejected when $\mu_{i} \neq \mu_{j}$ for at least one of the average scores and that $\mathrm{H}_{1}$ is the opposite assumption.

Statistical representation of this assumption is as follows:

Based on the findings of the tests and because the calculated $\mathrm{P}$-value is always greater than the error level, there is no reason to reject $\mathrm{H}_{0}$ about the effect of the color of the product on purchase behavior. Therefore, there is no meaningful difference in respondents views based on academic paper about the effect of the color of the product on purchase behavior among four different groups. However there is a meaningful difference in the mean of respondents' views at error level of $5 \%$ about the effect of size and design of the product on the purchase behavior of consumers.

Table 7. single-agent variance analysis for examination of respondents' view based on academic paper

\begin{tabular}{|c|c|c|}
\hline Assumption & F & P \\
\hline $\begin{array}{c}\text { Color of } \\
\text { product }\end{array}$ & 2.136 & 0.100 \\
\hline $\begin{array}{c}\text { Size of } \\
\text { product }\end{array}$ & 2.779 & 0.045 \\
\hline $\begin{array}{c}\text { Design of } \\
\text { product }\end{array}$ & 2.967 & 0.035 \\
\hline
\end{tabular}

\section{Examination of respondents' views based income}

In order to measure the meaningfulness of the difference of respondents' views based on income, a single-agent variance analysis was used. Here again $\mathrm{H}_{0}$ assumption, that there is no meaningful difference in respondents' views, is rejected when $\mu_{i} \neq \mu_{j}$ for at least one of the average scores and that $\mathrm{H}_{1}$ is the opposite assumption. Statistical representation of this assumption is as follows: 


\section{$\Lambda$ Macrothink}

Business and Economic Research ISSN 2162-4860 2013, Vol. 3, No. 2

Based on findings shown in table 8 and the calculated P-value, there is no meaningful difference in the average scores of respondents' views based on income about the effect of color and size of the product on behavior among 5 different groups. Therefore the views of people with different incomes about color and size of product on consumer behavior is the same with $90 \%$ confidence). However, an error level of $1 \%$ and consequently $5 \%$ of the views of respondents with different levels of income about the effect of product design on consumer behavior is different.

Table 8. single-agent variance analysis for examination of respondents' view based on income

\begin{tabular}{|c|c|c|}
\hline Assumption & $\mathrm{F}$ & $\mathrm{P}$ \\
\hline $\begin{array}{c}\text { Color of } \\
\text { product }\end{array}$ & 1.321 & 0.267 \\
\hline $\begin{array}{c}\text { Size of } \\
\text { product }\end{array}$ & 0.509 & 0.729 \\
\hline $\begin{array}{c}\text { Design of } \\
\text { product }\end{array}$ & 5.929 & 0.000 \\
\hline
\end{tabular}

\section{Ranking of criteria using Freidman test}

Based on the output of the Freidman test, the color of packaging is the most important criterion influencing the purchase decision of customers. The design of packaging and size of packaging are the next preferences.

Table 9. Freidman test for the ranking of packaging criteria

\begin{tabular}{|c|c|c|}
\hline Criteria & Friedman rank & Normalizes rank \\
\hline Color of packaging & 2.21 & 0.368 \\
\hline Size of packaging & 1.61 & 0.268 \\
\hline Design of packaging & 2.18 & 0.363 \\
\hline
\end{tabular}

\section{Conclusion and Suggestions}

Based on the findings obtained from the theoretic and the field studies in the present research, the following results and suggestions can be offered:

1- Since the color of packaging influences consumer behavior, food producing companies should be more careful about the coloring of food packaging. More specifically, customers in any gender, income and level of education believe that the packaging color of the product influences the amount of product that will be purchased.

2- Findings of the research show that if the products are offered in smaller packages, the tendency to buy the products increases. Food producing companies should know that large and big packages make the process of purchase and transportation of the product difficult. In addition, because foods have an expiration date, customers do not like large packages of products. 


\section{Macrothink}

Business and Economic Research ISSN 2162-4860 2013, Vol. 3, No. 2

3- Design of packaging also influences food consumers' behavior. Food producers should know that a beautiful package of food increases the appetite and desire to eat food and persuades the customer to buy it. The packaging design of the product has a positive effect on the buyer's taste. The design of the package has a direct effect on the prestige of its contents and even on the confidence of the consumer.

\section{References}

Golchinfar, Shadi, Bakhtaei, \& Amir. (2005). Internet; an efficient tool at the service of propaganda, Daneshe Tablighat (knowledge of propaganda), monthly magazine, No 10.

Hawkins, D, Best, R., \& Coney, K. (2010). Consumer Behavior: Building Marketing Strategy. (9th.ed.). New York: McGraw-Hill.

Moon. C. G., \& Minor, S. M., (2004). consumer behavior (first volume), Translation Abbas Saleh Ardestani, Tehran: Asar Press, (Original publication year 1993).

Peter, P. C., \& Olson , J. (2009). Consumer Behavior and Marketing Strategy. (7th.ed.). New York: McGraw-Hill.

Roosta, Ahmad, Venus, Davar \& Ebrahimi, Abdolhamid. (2007). Marketing management, Tehran: Samt Press, Sixth edition.

Serka, Walter. (2005). Principles of packaging technology: recognition: A look at packaging process, Packaging functions, graphic design, Translation: Hashem Habibi, Tehran: Hirad Press, First edition.

Silayoi, P., \& Speece, M. (2004). Packaging and purchase decisions: An exploratory study on the impact of involvement level and time pressure, British Food Journal, 106(8), 607-628.

\section{Copyright Disclaimer}

Copyright reserved by the author(s).

This article is an open-access article distributed under the terms and conditions of the Creative Commons Attribution license (http://creativecommons.org/licenses/by/3.0/). 